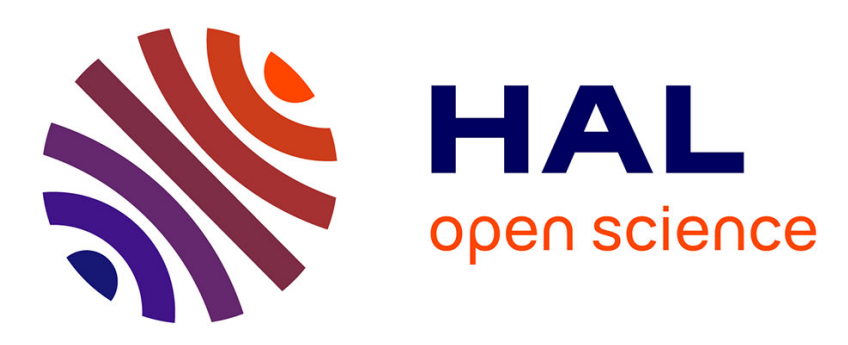

\title{
Designing mobility: pervasiveness as the enchanting tool of mobility
}

Annie Gentes, Camille Jutant, Aude Guyot-Mbodji, Michel Simatic

\section{To cite this version:}

Annie Gentes, Camille Jutant, Aude Guyot-Mbodji, Michel Simatic. Designing mobility: pervasiveness as the enchanting tool of mobility. MOBICASE 2009: Workshop on Innovative Mobile User Interactivity, Oct 2009, San Diego, California, United States. pp.401 - 409, 10.1007/978-3-642-126079_28. hal-01356681

\section{HAL Id: hal-01356681 \\ https://hal.science/hal-01356681}

Submitted on 26 Aug 2016

HAL is a multi-disciplinary open access archive for the deposit and dissemination of scientific research documents, whether they are published or not. The documents may come from teaching and research institutions in France or abroad, or from public or private research centers.
L'archive ouverte pluridisciplinaire HAL, est destinée au dépôt et à la diffusion de documents scientifiques de niveau recherche, publiés ou non, émanant des établissements d'enseignement et de recherche français ou étrangers, des laboratoires publics ou privés. 


\title{
Designing mobility: pervasiveness as the enchanting tool of mobility
}

\author{
Annie Gentes, Camille Jutant, Aude Guyot, and Michel Simatic \\ Institut Télécom - Telecom ParisTech \\ 46 rue Barrault Paris F75013 \\ Institut Télécom - Telecom SudParis \\ 9 rue Charles Fourier Evry F79011 \\ \{gentes, camille.jutant, aude.guyot, michel.simatic\}@telecom- \\ paristech.fr
}

\begin{abstract}
PLUG - Play Ubiquitous Games -, is a research project that deployed a fully distributed RFID architecture in the Museum of Arts and Crafts in Paris. A pervasive game was designed: "Plug: the Secrets of the Museum" (PSM) where players had to find virtual representations of the Museum artifacts, scatter them around or tidy them in the right spots, or swap them with other players. The analysis of the players' feed back showed that three main features characterize mobility when it is connected to pervasiveness. First, mobility appears as a way to read and collect information. Second, it is a tool to virtually mark the environment and the artifacts. Moving can be akin to "writing" a new scenario. Third, people become part of the network propagating and refreshing information not only on their mobiles but also on the RFID displays.
\end{abstract}

Keywords: Mobile entertainment, mobile multimedia, mobile and contextaware games, novel user experience and interfaces

\section{Introduction}

Mobile and pervasive applications depend on different parameters pertaining to concrete and specific situations. These applications are not a purely virtual world as in videogames but a mix of reality and fiction [15], that rely not only on technological rationale but also on physical and cultural contexts on the one hand and types of mobility on the other hand. Designing pervasive applications means taking the mobility in context or risk contradict what people expect from the situation, their feel for it, what they deem an appropriate behavior. This paper is an attempt at rendering the different planes of experience of a mobile pervasive game that we developed in the context of a museum, so that we might infer some guidelines for the conception of mobile pervasive applications "on the threshold between tangible and immaterial space" [18].

In the project PLUG, an interdisciplinary team including curators of the Museum of Arts and Crafts in Paris (Musée des Arts et Métiers) where the game was deployed, game designers (Tetraedge), media and design researchers, and researchers in computer science (CNAM, Institut Telecom) organized a game based on RFID tags 
Designing mobility: pervasiveness as the enchanting tool of mobility

that was to entertain the visitor, create a special bond with the museum, and contribute to a better understanding of the artefacts. As we tested the game, we soon realized how much the mobility introduced by our pervasive game challenged traditional mobility in the Museum.

Based on Michel de Certeau's distinction between «place » and « space », we shall argue that how one circulates in a «place» (i.e. an «instantaneous configuration of relations ») generates a «practiced space » (i.e. « informed by use ») [5]. Mobility says something about one's relation to a specific «place». Moves are not only a means to an end but a meaningful activity. This led us to analyze more specifically the questions of meaningful forms of mobility and how pervasive applications bring their own logic of mobility that can be confusing for the player/visitor.

After a description of the game, we present and analyze the results of our user tests based on observations, questionnaires and in-depth qualitative interviews that explore reactions, comparisons, recollections that the experience triggered ${ }^{1}$. The analysis of this feedback gives us insight into the dynamic between user and environment as an essential feature to mobile systems. Four types of mobility appeared that are enhanced by a pervasive system: first there is traditional gaming mobility such as running over obstacles or racing, where physical artifacts become anchors for the trajectory; second, the pervasive system turns mobility as a tool to "double read" the environment; third players can leave their mark and write in context; four pervasiveness provides a tool for sociability based on the co-presence of the actors.

\section{PLUG, The Secrets of the Museum}

\subsection{Other Mobile Experiments in Museums}

Pervasive technologies present an interesting potential for museums because they improve two characteristics of the visit [8]: the visitor's autonomy - as in "Visit +" in the Cité des Sciences et de l'Industrie in Paris where the user chooses to record data stored on a personal account and can retrieve after the visit [17] - and the precision of the information conveyed - as in "Soundspot", an entertainment system experimented in The Museum of Nature and Human Activities in Hyogo which is "a location/userdependent audio guide system. It can track the positions of visitors and provide audio information in the limited spots where they stand" [6]. In particular, RFID technology has been especially used by science museums to improve and augment visitor experiences - the Exploratorium in San Francisco with the eXspot system (visitors carry keepsake RFID cards) and the Electronic Guidebook Project [12]; or the Tech Museum in San Jose with the "TechTag" (children wear RFID tag wristbands that trigger exhibits and collect information) - but also to manage their collections (with location tracking systems) - the Industry and Science Museum in Chicago. A few games have also been implemented by museums. The closest project to our

1 These tests were conducted during two days (22 and 23 November 2008). Twelve game sessions were held, with a total of 96 teams and 150 players. 
experiment is Via Mineralia in the Terra Mineralia Museum in Freiberg that asks players to find a specific exhibit, answer some questions and earn points, with a PDA coupled to an RFID reader [11].

But all these uses of RFID presuppose the same type of mobility for all visitors: a linear progression from one artefact to the other. At each stop, information is delivered in "audioguide fashion", with top down communication. Visitors are not allowed to answer or to leave their mark within the Museum.

\subsection{Plug, the Secrets of the Museum}

The game "Plug: Secrets of the Museum" looks like the British «Happy Family » card game (or «Jeu des Sept Familles », in French) coupled with a quest based on RFID tags. The purpose of PSM is to discover the Museum by retrieving and collecting cards that represent 16 real objects in the Museum. The "card deck" is composed of four thematic families (for instance, the Ghost Busters family puts together famous scientists of the Museum).

Eight players can play together for one hour. They are equipped with a handset able to read/write RFID tags (in our project: Nokia 6131 NFC mobile phone) and with a map of the Museum (so that they can locate themselves and the real objects more easily). 16 passive RFID tags are spread throughout the Museum. Each tag is located on a display beside one of the real objects. Each tag contains 1 virtual card. To gain points, players must prove: their collector's ability, by gathering four cards of the same family on their handset; their public-spiritedness, by storing a card to its reference RFID display; their generosity, by swapping cards with other players; their curiosity, by answering quiz on the Museum artefacts.

At the start of the game, each player discovers her "hand" of virtual cards in the handset. She can "zoom" to get detailed information on the object. Then she sets out to find the tags and discover their contents. Players press their phones on the tag. The handset displays the virtual card stored in the tag. The player can, thus, exchange this virtual card with one of the four cards located in her handset. A player can also exchange cards with another player through the handset. The exchange takes place in peer-to-peer NFC mode [9].

The device enables the « reading » and the «writing» of virtual cards, gathered and exchanged among mobile phones and tags on display. The game difficulty stems from this double mobility: content mobility related to user mobility. 

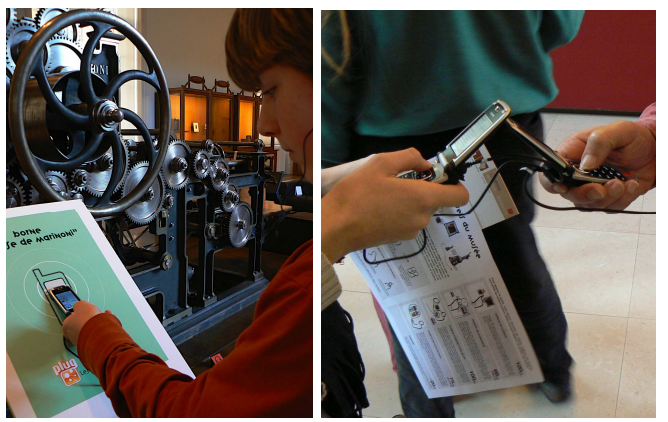

Fig. 1. Experiments in the Museum

\section{Pervasiveness as chaos}

Today, questions surrounding mobility and the nature of the museum visits are an integral part of museography. To understand the changes brought about by mobile pervasive applications, one must keep in mind that museums already foster certain types of mobility. The question is how do users juggle with traditional mobility and mobility induced by the mobile pervasive game at the same time.

The first answer is that players consider that their behaviour transgress traditional museum visits: they touch the displays, talk together, swap objects, and moreover rush to gather as many cards as possible.

"I was glancing at security agents, I was worried that they would call me back to order. After all, we run like mad men! It is rather against the Museum's (rules). Where mobiles are forbidden, and we cannot run nor shout".

Speed is considered as an inappropriate answer to the cultural situation and inadequate to get an in-depth knowledge of the artefacts. But this shortcoming of our game is rather independent of the impact of pervasiveness. Other reactions point towards the specific challenges raised by pervasive games.

\subsection{The museum conventions disrupted by scrambled visits: pervasiveness challenging orientation}

Even though it would be an oversimplification to imply that museum exhibitions format visits, it is important to accept the true measure of the norms and conventions involved, more or less acknowledged by visitors [13]. In addition to behavioral conventions, the visit relies on signs that organize the relation to and between the artifacts. The visitor recognizes formal aspects, and shares with the curator a common culture: an arrow is understood as an indication to "move further on in this direction"; a cartel signifies "stop here to find out more". The signs contribute to create meaning so as to help the visitor move in space (following, if the case may be, a story-line), and to understand what kind of relation to establish with objects on display 
(contemplation, comparison, manipulation...)" [10]. A whole set of signs strive to remove any ambiguity on what to look at and how to get at it.

In PSM, our scenography was also pretty explicit, as the 16 objects and RFID displays were located on a map given to the players before the start of the game. A majority of players explored all the destination points, and therefore visited almost all of the rooms in the museum, discovering some of them: "It allowed me to go to places I'd never have visited otherwise."

But the information is not "fixed" as players can change the contents of the display. In other words they can find a locomotive under the RFID tag of a loom and the loom card can be on somebody else's mobile phone. Because virtual cards are stored in both the RFID displays and handsets, players become mobile nodes of the network and change their trajectories to catch either the right player or the right display. In other words, mobility is not just a by-product of the game but rather its driving force with an unpredictability of moves that is related to the mobility of contents and players.

As a consequence, testers considered that their trajectory was less "logical" than during a more conventional visit. "Generally, in a museum, there's a "direction" and, well, here, we forgot about that entirely. You don't notice the path taken, it's completely arbitrary when compared to the traditional visit. It's very free." Standard visits were felt as rather disciplined, whereas PSM circuits were considered much more disorganized, "scrambled" as was shown by the drawings that the players made of their moves in the Museum. The two drawings below illustrate how the players represent a normal visit to the museum and a visit with PSM $^{2}$.

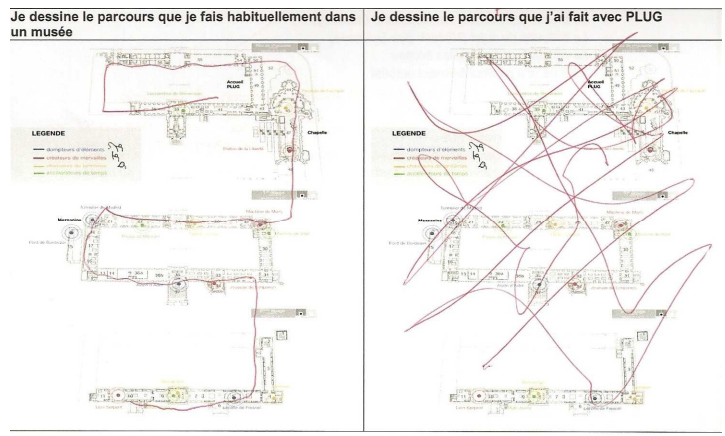

Fig. 2. Representations of PSM trajectories

Indeed, observing the deployment of the game, we realized how much we disrupted the expected and institutionalized mobility within the museum. The move from one RFID tag to another opens up a whole range of options during the visit. If pervasiveness is not used to replicate the mobility in place in the Museum, it introduces a mobility with its own rules that can change the way people orientate

2 Players were asked to draw first their normal trajectory, then the trajectory induced by the game. 
Designing mobility: pervasiveness as the enchanting tool of mobility

themselves or decide where they want to go. The difficulty for players is to partly disregard their usual orientation process.

\subsection{From univocal text to double narrative}

As the orientation process is challenged, the narrative of the Museum is also disrupted. In a Museum, objects function as words, articulated so as to produce meaning [2]. Davallon underlines that "understanding is rooted in the way objects are presented" [3]. Creating an exhibition has been compared to directing a play or writing a scenario [7]. To this extent, the exhibition must provide the visitor with "a consistent story-line that engages the viewer to pursue her visit, so as to discover how it ends" [4]. This linear de-ambulation, - with its characteristic ambiance, tempos, breathing spaces, - is punctuated by panels and captions that " help us wend our way through the narrative structure of the show. A panel must be situated at each important stage of the intrigue, thereby signaling the beginning of a new episode" [16]. Ideally, one unit of meaning segues into another, without any back-tracking, and is followed through until the end of the tour.

With PSM, we did not want to contradict the Museum discourse. On the contrary, we were bent on reinforcing the understanding of the Museum and did so by introducing questions and information about the artifacts. Nonetheless we offered another "grammar" that overlapped the existing one. Each artifact no longer belonged to a group of similar technical objects (as they are organized in the rooms of the Museum) but was related to a human quest: embellishing nature, mastering time... Though in no way contradictory to the "first" narrative of the Museum, pervasiveness introduces not so much an ambiguity as is argued by Bjork [1], but a double reading based on a new layer of text. In our experiment, it was felt as unsettling though not necessarily in a negative way. It shows that there is no definite narrative and it highlights the fact that the Museum can present its artifacts in many different ways. This is no surprise to museum professionals but for the users it undermines the assumption that there is one and one only possible discourse. It opens the way to questioning the choices and to participating in their making.

\section{4 "Writing" in the Museum Space: a way of Creating Meaning}

If players testified of the increasing complexity of the experience they also considered that the pervasive system gave them a new tool to handle their mobility as it allowed them not only to read but to write and to create their own narrative.

Testers explained that, unlike audio-guides (the only other mobile device they had encountered) "PSM" pervasive structure allowed them to carry and share contents as they could remove the virtual cards and deposit them at another display. Testers asserted that the NFC mobile enabled them to write. "Here I transpose something onto the display, whereas usually, it's not like that, it's the other way around. Usually you're told, "Go here, listen to the commentary!' You're not the one to carry the information, unlike here." 
Some compare the phone to a magic wand. "While there it's me, I can give something at any point in the trajectory. That's unique."

By marking the place and its artifacts, the visitor becomes a collector and the author of her visit. "I bring my contribution to the system. I complete it, right, it's fun but it's also as if there were a gap, something missing and 'bingo!' I find the missing bit, I finish the Lego and 'wham!' I manage to make it whole, like a construction. There's participation, there's choice, you have to decide, choose the card, find it, identify it. Then there's the swapping in the Museum. In a way we've appropriated ourselves of the Museum space, we know that we've left a small trace of ourselves..."

Mobility was felt as a way to reorganize and rewrite their access to culture through an active personal but also collective participation.

\section{Shared mobility: Collective Writing}

The chaos brought about by the moves of virtual cards and players is not only reduced by the act of collecting and rewriting the overall access to cards. Mobility was finally perceived by the players as a global question involving everybody and soon they tried to organize a global view of the situation and they tended to stabilize the positioning of cards.

The game encouraged social interactions to gain card but also to score in "generosity". People met, looked at each other's screens and, if they wanted to exchange a card, brought their phones together." It allows you to interact with other people. If you have an audio-guide...there's the aspect, well here I am and now I'll put on my earphones...two hours can go by and nobody speaks to you, you're isolated from each other. Whereas here, there's the interactive side, you can fool around together..."

Such trust is made possible by the specific environment. The context guarantees the civility of the exchanges. First, people share the Museum that is considered a safe place. It is a closed space, with security and guards. Contrary to other experiments that we did in railway stations [7], nobody expressed the fear of being mugged or harassed. It is also safe because being in a Museum signifies sharing a common interest. People who choose to go to the Museum belong to a real, if transient or ephemeral community. There is the social assumption that museum goers are "of the same world". The game itself, as it is issued by the Museum, benefits from a qualified aura. It cannot be a superficial entertainment. Playing the game is therefore playing under the authority of the Museum that allows and even encourages relationships between visitors. Moreover, the device (phone plus RFID) and the gestures that are associated to it set players apart. They signal a "shared categorical identity" [14]. Because of this shared situation and common identity, players agree to communicate with strangers.

We also observed two types of behaviors that turned the game from an individual quest to a collective rewriting. First, some players call the others to let them know 
Designing mobility: pervasiveness as the enchanting tool of mobility

what card they came across. This gives a more comprehensive view of the situation. Second, because civil behavior is promoted within the game (by tidying the cards in the Museum), the individual activity is not only rewarded, it introduces a possibility of anticipation that leads to a collective interest. The players know that if everybody plays "civic", it will be easier to know where the cards are and to reduce the chaos induced by the everchanging position of cards. In our tests, they banked on this collective behavior.

\section{Managing a double sociability}

Mobility is therefore perceived as a condition to meeting people not only as potential enemies/allies in the game but also as people engaged in the same meaningful mobility and therefore potentially in relation to each other. This mobility also sets apart from other visitors of the Musem. Players involved in pervasive systems have to decide how to ignore or involve other people. What kind of relationships is established between gamers and non gamers? Is it a way to influence others to get into the play (out of sheer curiosity)? Beyond games how can mimicry be a social tool for mobile services?

Pervasive games create situations where players must manage a double sociability: the community of players and the community of non players sharing the same social space. They cannot ignore the rules of mobile behavior in the Museum.

\section{Conclusion: Design Lessons in pervasive applications}

Designing pervasive applications can be a lot of fun but it includes a lot of damage control. If the pervasive application does not replicate exactly the audioguide (and in that case why should we even bother to think of developing pervasive games), the users have to show a capacity in running two levels of constraint on a certain number of issues. How to read a double narrative - one already in place in the Museum and one that belongs to the game? How to superimpose or twin together the Museum information, our own and that of the other players in a collective writing? How to deal with at least two communities, one "in" the other "out of" the game? Each decision involves a certain type of mobility but mobility itself then has a double meaning. First, mobility is meaningful because it involves some kind of relationship to the context that can be defined as a tangible reality (building, walls, windows, openings, obstacles) but also a social one. Second, mobility is meaningful because there is a "pervasive agenda". Our game tried to rely on the institution as a cultural entity where people adopt what they consider the proper behavior but also the correct situation of communication. Museums are places of civil behavior that are disrupted by the proposal of a game and both institution and players won't push the situation too far from the requirements of the situation. This engages a political model of mobility and pervasiveness. 


\subsection{The museum conventions disrupted by scrambled visits: pervasiveness challenging orientation}

If mobility is perceived as a way to create a meaningful experiment by linking some places, objects together in a more or less loose association, a form of narrative, it is important that designers should first consider space as a "reservoir of resources" to use Heidegger's words. The space around us contains, organizes and feeds our activities. These resources have to be defined as they are not necessarily useful for an activity but meaningful in a narrative. In any event, contents must be organized as items that can be reorganized through the moves of the users. Designing mobility means designing bits of information that can be "walked" together in a creative way, leaving the user to build her phrase, her narrative as in an Exquisite Cadaver or Queneau's A Thousand Billion of Poems. Each fragment can be re-configured. Each time the user is confronted to a new piece of information, image or text, she considers it not only in its own right but also as it is going to be part of a composition that makes sense both of the item and its context.

\subsection{Creating double layers of text}

Designing pervasiveness means studying the museum as a second page. Players did not want to annoy the other visitors.

"There were lots of people in front of the display. I had to push them a little to be able to plug in".

To design mobile pervasive applications one has to clearly outline the status of the different places and if they are suitable or not for a "second" layer of writing and reading. This has to do not only with comfort and access but also with the representations of the place: is it a suitable and legitimate place to write? It also means that the environment must be designed so as to produce signs and affordances that help understand that this is indeed the right place to read or write.

For the museums, what is at stake is obviously reconsidering the way they handle visitors. The problem is not to deprive the cultural institution of its legitimacy in terms of knowledge and heritage, but to pursue the reflection on how to impart this knowledge. Designing Plug: The Secrets of the Museum, we therefore discovered that not only should the environment be taken into consideration, but also the moves with their predefined meanings and their potential to include new significations as well as significant potential for trouble.

\section{References}

1. Björk, S.: Changing Urban Perspectives. In: Borries, F., Walz, S., Böttger, M., Space Time Play, Birkhäuser (2007)

2. Cameron, D.: Un point de vue: le musée considéré comme système de communication et les implications de ce système dans les programmes éducatifs muséaux, [1968]. In: Desvallées, 
Designing mobility: pervasiveness as the enchanting tool of mobility

A. : Vagues: Une anthologie de la nouvelle muséologie, vol. 1, Éd. W/MNES, Mâcon/Savigny-le-Temple (1992)

3. Davallon, J.: L'Exposition à l'œuvre: Stratégies de communication et médiation symbolique. L'Harmattan, Paris (1999)

4. De Bary, M.O., Tobelem, J.M.: Manuel de muséographie. Petit guide à l'usage des professionnels de musée, Séguier/Option culture, Biarritz (2000)

5. De Certeau, M.: L’invention du quotidien, Tome 1, Arts de Faire, Folio, Paris (1980)

6. Deguchi, A., Mizoguchi, H., Inagaki, S., Kusunoki F.: A Next-Generation Audio-Guide System for Museums 'SoundSpot': An Experimental Study, Lecture Notes in Computer Science, Springer, Heidelberg (2007)

7. Edson, G., Dean, D.: The Handbook for Museums, Routledge, Londres and New York (1996)

8. Gentès, A., Jutant, C.: Pervasive gaming: Testing future context aware applications, Communications and strategies, no. 73 (2009)

9. Gentès, A., Jutant, C., Guyot, A., Simatic, M.: RFID technology: fostering human interactions", IADIS Game and Entertainment Technologies (2009)

10. Gob, A., Drouguet, N.: La muséologie: histoire, développements, enjeux actuels, Armand Colin, Paris (2006)

11. Heumer, G., Gommlich, F., Jung, B., Müller, A.: Via Mineralia - A Pervasive Museum Exploration Game. Proceedings of Pergames 2007, Salzburg, AT (2009)

12. Hsi, S.: The Electronic Guidebook: A Study of User Experiences using Mobile Web Content in a Museum. Institute of Electrical and Electronics Engineers, International Workshop on Wireless and Mobile technologies in Education. IEEE. Danvers (2002)

Hsi, S., Fait, H.: RFID: Tagging the World: Rfid Enhances Visitors' Museum Experience at the Exploratorium. Communications of the Association for Computing Machinery, 48(9) (2005)

13. Le Marec, J.: Publics et musées: la confiance éprouvée, L'Harmattan, Paris (2007)

14. Liccope, C., Inada, Y.: Les usages émergents d'un jeu multijoueur sur terminaux mobiles géolocalisés », Réseaux, vol.5, $\mathrm{n}^{\circ} 133$ (2005)

15. Montola, M., Stenros, J., Waern, A.: Pervasive Games. Theory and Design., Morgan Kaufmann (2009)

16. Sunier, S.: Le scénario d'une exposition. In: Publics et Musées n¹1-12, Actes Sud, Arles (1997)

17. Topalian, R.: Visite+: personnalisation de la visite et site mémoire des visites culturelles, Culture et Recherche, $\mathrm{n}^{\circ} 112$, Paris (2007)

18. Walther, B. K.: Atomic Actions - Molecular Experience: Theory of Pervasive Gaming, CIE, ACM, New York (2005) 